\title{
LA GESTUALIDAD: SIGNIFICACIÓN Y ESTÉTICA DEL ROSTRO Y LA EXPRESIÓN CORPORAL
}

\section{GESTURES: MEANING AND AESTHETICS OF THE FACE AND BODY LANGUAGE}

Lucio Blanco Mallada: Facultad de Ciencias de la Información de la Universidad Complutense de Madrid (España)

lucio.blanco@ccinf.ucm.es

\section{CURRÍCULUM VITAE}

Profesor Doctor de la Facultad de Ciencias de la Información de la Universidad Complutense de Madrid y en la Universidad SEK de Segovia. Su área como docente son las relacionadas con la televisión y la realización audiovisual.

\section{RESUMEN}

Este artículo trata de poner en relación cuanto supone la gestualidad con su significación en el marco de la comunicación audiovisual. El rostro y el cuerpo se expresan por medio de técnicas que también han sido estudiadas en el campo de la comunicación no verbal dando un rango científico a la técnica de la interpretación. Antes de mostrar el rostro los actores llevaban ante él una máscara. Ésta definía cada carácter y cada rol interpretativo. El propio gesto crea un sentimiento. Según varios experimentos, existen unos movimientos faciales determinados para expresar cada uno de los estados afectivos primarios o emociones fundamentales que son: 
felicidad, ira, sorpresa, tristeza, disgusto y miedo. Existe una gran diferencia entre los diferentes ámbitos culturales.

\title{
PALABRAS CLAVE
}

Gesto - Rostro - Comunicación No Verbal - Mirada - Aspecto externo

\begin{abstract}
This article attempts to relate that it involves the gesture to its significance in the context of audiovisual communication. The face and body are expressed by means of techniques have also been studied in the field of nonverbal communication to give a scientific status to the art of interpretation. Before showing the actors wore the face mask before him. It defined each character and each role interpretation. The gesture itself creates a feeling. According to several experiments, there are a certain facial movements to express each affective states primary or fundamental emotions are: happiness, anger, surprise, sadness, disgust and fear. There is a difference between the various cultural spheres.
\end{abstract}

\section{KEY WORDS}

Gesture - Face - No Verbal Comunication - Look - External appearance

\section{ÍNDICE}

1. Los atributos de la gestualidad

2. El papel de la comunicación no verbal

3. Bibliografía

4. Notas 


\section{TEXTO}

\section{Los atributos de la gestualidad}

1.1. Antes de mostrar el rostro los actores llevaban ante él una máscara. En ésta se mostraban unos determinados rasgos faciales de modo que cada máscara representaba un determinado tipo: el valiente, el leal, el rufián...más que una persona se trataba de mostrar una personalidad, un comportamiento. La máscara, de modo genérico, mostraba los rasgos que, de inmediato, hacían que el público comprendiera quien era quien antes incluso de ver cual era su comportamiento. De un modo puramente denotativo la máscara definía cada carácter y cada rol interpretativo. Claro que en el teatro clásico, donde nace la interpretación, no se trataba de poner en el escenario una persona con la complejidad psicológica que podemos encontrar en las interpretaciones actuales. Se trataba más bien de representar una idea abstracta: la venganza, la fidelidad, el valor, la traición de modo que los rasgos genéricos que se mostraban en las máscaras eran de gran eficacia para "conocer" de inmediato a cada actuante y saber lo que se podía esperar de él con lo cual la máscara pasaba a ser un elemento clave de la estructura narrativa.

De una parte la máscara desenmascara nuestro propio yo, nuestra propia identidad, al hacer aflorar rasgos que todos tenemos en nuestro carácter. La vida, el rol vital promueve un carácter. Una manera de ser, una determinada personalidad implica un determinado discurso gestual, y la repetición de unos mismos gestos hace que se formen en las caras unos determinados rasgos. De acuerdo con (Davis, 1992 69) "En bastante medida el hombre es capaz de controlar su rostro y utilizarlo para transmitir mensajes. También se refleja en él su carácter, dado que las expresiones habituales dejan huella". Una mirada, una sonrisa implican la actividad de unos determinados músculos faciales. Así, al repetirse la actividad de unos mismos músculos el rostro se va configurando haciéndose notar especialmente unos rasgos. Cumpliéndose los 
tópicos tales como que un juez tiene una mirada inflexible y jamás sonríe, un policía tiene una mirada escrutadora, una buena persona es sonriente, etc., se comprende que una manera de mirar, una manera de sonreír repetidas significan que unos mismos músculos faciales están actuando repetidamente con lo cual se comprende la formación de unos rasgos faciales característicos.

De otra parte la máscara enmascara nuestro propio yo, nuestra propia identidad que queda tapada por los rasgos que pertenecen a todas las personas con características similares. .

Así pues la máscara potencia una personalidad, un desarrollo individual y al mismo tiempo trasciende lo individual, generaliza lo particular. En esta dialéctica generalindividual, concreto-abstracto, característico-típico se enmarca la máscara y después el rostro.

1.2. Otra dialéctica en la que se enmarca la interpretación es la de pensar y sentir. ¿Llegar a la composición del gesto por la vía racional, mediante el conocimiento, o crear un impulso interno, un sentimiento, que haga brotar el gesto del mismo modo que esto ocurre en la vida real? ¿Pensar o sentir? La respuesta la da maría Zambrano cuando dice que pensar es saber lo que se siente.

Para la mayoría de los directores e intérpretes el camino va del sentimiento al gesto pero esto no es siempre así. Algunos de los más importantes nombres de la historia del cine proponen el camino contrario, entre ellos Eisenstein quien afirmaba que no lloramos porque estamos tristes sino que estamos tristes porque lloramos. Indudablemente lo que Eisenstein quiere decir es que lo que el público sabe es aquello que ve y lo que ve es el gesto y no el sentimiento. 
Lo que realmente afirma Eisenstein es que el mismo gesto crea el sentimiento. Un golpe con el puño contra una mesa no solo hace saber al espectador que alguien está furioso sino que crea un sentimiento de furia en el intérprete.

1.3. La tercera dialéctica se establece sobre el grado en que el gesto debe mostrarse, lo explícito o lo contenido del gesto que se debe, sin duda, al estilo interpretativo y éste al conjunto de técnicas como la óptica, la iluminación, la escenografía, un conjunto orgánico que crea una estructura en la que se entrelazan todos los elementos. De acuerdo con esta estructura la interpretación puede ser muy explícita o contenida. La interpretación con abundancia de gestos, posturas y todo tipo de resortes interpretativos suele ser calificada de teatral. En el cine mediante la óptica, el acercamiento del punto de vista y el montaje no se da la necesidad de una interpretación tan visible y fácilmente identificable.

La diferencia entre la interpretación teatral más obvia y la cinematográfica más sugerente y sutil ha sido señalada desde los primeros años del cine. Ya (Pudovkin, 1972:11) se refería al problema de la interpretación del actor teatral: "Para eso, para ser claramente percibido y oído por la mayor parte de los espectadores el actor estudia dicción, educa la voz, aprende a exagerar los gestos...de manera que se le pueda ver y oír desde la última fila, pero cuanto más amplio es el gesto del actor tanto más reducida se hace en él la posibilidad de matices ". Eisenstein cita al actor George Arliss quien explica en sus memorias como siempre había creído que en el cine había que exagerar la interpretación pero había llegado a comprender que la sobriedad era la cosa más importante que un actor tenía que aprender al trasladar la interpretación del teatro a la pantalla (ver Nota 1). La sobriedad puede llegar hasta la alusión a la acción que no es algo fácil de llevar a la práctica pues el gran público exige una mayor claridad, pero podemos hallarla en cineastas minoritarios entre los que destaca claramente R. Bresson por su minimalismo en la interpretación como en todo el conjunto de técnicas de expresión. El minimalismo de Bresson ha hecho 
escuela pudiendo encontrar ese estilo en varios directores de la Nouvelle Vague como Louis Male o Claude Chabrol y más actualmente en directores como Jim Jarmusch o Denys Arcand.

En términos generales la interpretación en la actualidad tiende a la sobriedad. Incluso habida cuenta de las diferencias de estilo en los autores y de las diferencias de estilo en los distintos géneros (la comedia admite una exacerbación interpretativa que no admite ningún otro género normalmente) podemos observar que en el cine postclásico hay una marcada tendencia hacia un estilo interpretativo mucho más sobrio que en el cine clásico. Igualmente se puede observar que el cine fuera de géneros tiene generalmente una interpretación más contenida y sobria que el cine de géneros lo cual nos vuelve de nuevo a la dialéctica entre lo típico y lo característico, lo general abstracto y lo individual concreto pues el cine de géneros tiende más a representar tipos, más cercano a lo abstracto, que personas altamente individualizadas con un perfil más ambiguo y menos definido. El tipo no excluye alguna contradicción en su comportamiento lo cual forma parte de la estrategia narrativa clásica pero no opera en una escisión sistemática del sujeto. El sujeto escindido y en contradicción permanente obliga a una indagación en las profundidades de la psiqué imposible de realizar con una interpretación genérica y normativa a la que nos referimos con el nombre de teatral, son necesarios aquellos matices a los que se refería Pudovkin..

1.4. Una cuestión en permanente debate es la naturalidad. ¿Debe la interpretación ser natural, en el sentido de no apartarse del gesto hecho en la vida común por las personas comunes, o debe alejarse, como toda poética, de ese referente que es la realidad de lo común cotidiano?

El gesto es algo que se inscribe en el ámbito de la acción y de la comunicación. En esos ámbitos se debe distinguir entre el hacer equivalente a la palabra latina agere y 
el hacer equivalente a la palabra latina facere. En palabras de (Agamben,1992:34) "En effet, il est posible de faire quelque chose sans l'agir; par example, le poete fait un drame, mais il ne l-agit pas (agere signifiant ici “jouer un rol”); inversment, l'acteur agit le drame mais ne le fait pas" (ver Nota 2). Una tercera raíz latina, res gerere, tiene el significado de completar una acción, tomarla sobre si asumiendo la entera responsabilidad. Según Agamben lo que caracteriza al gesto no es el hacer ni en el sentido de facere ni en el de agere sino el asumir y soportar. Desde luego la etimología de la palabra gesto no deja lugar a dudas, la declinación del verbo gerere: gero, gerere, gestum, deja clara la procedencia de la palabra. Pero “ ¿cómo una acción es asumida y soportada? ¿Cómo una res se convierte en res gesta?" se pregunta (Agamben1992:34). La respuesta nos lleva hasta Aristóteles en el que aparece, en último término, la distinción entre facere y gerere. El género del gerere es el género de la praxis mientras que el de facere es el género de la poiesis. Mientras el facere tiene un fin distinto a si mismo el agere es en si mismo su propio fin. Ese tercer género de acción que es el gerere introduce una novedad muy importante. Mientras facere es un medio con vistas a un fin agere es un fin sin medios. Habría pues una categoría de medios subordinados a un fin y otra categoría superior de "el gesto en tanto que movimiento teniendo en si su propio fin". La marcha como medio de desplazar un cuerpo de un punto a otro sería ejemplo de la primera, la danza como dimensión estética sería ejemplo de la segunda. Según Agamben la danza es gesto porque consiste en soportar y exhibir el carácter medial de los movimientos corporales. Así el gesto consiste en exhibir una medialidad, en hacer visible un medio como tal.

Así pues en el gesto hay una dimensión de pura finalidad que es la de transmitir al espectador el conocimiento sobre la evolución de los personajes y del relato y otra dimensión a la que podríamos llamar al modo kantiano una "finalidad sin fin", dicho de otro modo una medialidad sobre la que se constituye la estética de la interpretación, la separación del gesto común y cotidiano, del realismo o del 
naturalismo, para dar cabida a la exhibición. Ambas juntas darían como resultado la res gesta, el carácter completo del gesto asumiendo toda la acción, la suma de la finalidad y la medialidad.

\section{El papel de la comunicación no verbal}

2.1. Decía Kretschner que el rostro es la expresión comprimida de la fórmula constitucional psíquico-física. En efecto los experimentos llevados a cabo mediante el estudio de individuos de diferentes culturas, diferentes espacios geográficos, diferentes edades, diferentes sexos ha dado como resultado la constatación de que existen unos movimientos faciales determinados para expresar cada uno de los estados afectivos primarios o emociones fundamentales que son: felicidad, ira, sorpresa, tristeza, disgusto y miedo.

Quien comenzó las investigaciones sobre las expresiones faciales fue Ekman quien tratando de encontrar un método fiable para descifrarlas encontró una especie de atlas del rostro llamado FAST ( Facial Affect Scoring Technique)

Se han distinguido tres zonas del rostro. Cada una de las emociones fundamentales se registra más acusadamente en unas zonas que en otras. La zona alta es la que forman cejas y frente, la zona media la formada por ojos, nariz y parte alta de las mejillas y la zona baja que comprende la boca y la parte baja de las mejillas. Las zonas en las que se registran cada una de las emociones es ésta:

felicidad: parte inferior y ojos

ira. parte inferior con frente y cejas

sorpresa: parte inferior, ojos y cejas, si es muy fuerte también frente 
tristeza: ojos y cejas

disgusto: zona inferior

miedo: las tres zonas con énfasis en los ojos.

A pesar de la afirmación de Kretschner los rasgos proporcionan datos objetivos sobre cuestiones generales como edad, sexo o raza, pero solo impresiones sobre la personalidad. Frente alta, gafas, piel áspera, cabello encrespado son datos que sirven para enmarcar una persona en un tipo y así vemos como en un género western, thriller, terror, etc. aparecen diversos tipos que efectivamente muestran ciertas características comunes. Aun así los matices de una persona son muchos y los rasgos no pueden llegar a descubrir todas las características personales de un individuo.

Incluso las emociones podrían ser fingidas. Hay un control en el nivel consciente que funciona inhibiendo y exhibiendo emociones. Desde la infancia aprendemos a ocultar emociones y a fingir otras, a veces incluso superando las intenciones. Aparte del fingimiento la socialización hace que las emociones sean manipuladas, enfatizadas o negadas debido a las reglas sociales de corrección, respeto, reserva. Siguiendo a (Davis, 1992:73) en todas las culturas existen unas "reglas demostrativas que definen cuales son las expresiones apropiadas a cada situación. Estas reglas pueden exigir que una expresión sea moderada, ocultada o suprimida por completo". La misma autora señala que cada cultura cuenta además con sus propias reglas y con su propio estilo facial. Las culturas cuyo comportamiento facial es muy expresivo y cambiante, como los italianos, encontrarán difícil sondear el rostro de los ingleses que es generalmente muy controlado.

También debemos tener en cuenta las expresiones denominadas "micromomentaneas" o "micros" que no constituyen por si solas mensajes 
conscientes o inconscientes, sino que según (Davis, 1992:76) "son filtraciones de sentimientos verdaderos. En realidad pueden servir como una válvula de escape que permite a una persona expresar, aunque sea muy brevemente, sus impulsos o sentimientos inaceptables".

2.2. El comportamiento visual es de una gran variedad y complejidad. En el lenguaje cotidiano utilizamos expresiones tan variadas como: observar atentamente, mirar de forma torva, dar una ojeada, escrutar, contemplar...todo son matices de una forma de mirar.

Jean Paul Sartre afirmaba que el contacto visual es lo que nos hace real y directamente conscientes de la presencia del otro como ser humano. No parece exagerado decir esto si tenemos en cuenta todas las acciones que los ojos pueden realizar. Pueden hipnotizar, atraer, esquivar, seducir, desafiar, lanzar miradas de odio. El individuo siempre se ha preocupado por la mirada y sus efectos en la conducta humana, así lo atestiguan un gran número de frases utilizadas frecuentemente en el lenguaje popular.

El significado de la mirada varía según la dirección y la duración. Una mirada corta es un proceso de señalamiento, una adquisición de información. Una mirada larga significa interés sea éste sexual, afiliativo o agresivo-competitivo. Un uso demasiado intenso de la mirada puede interpretarse como una invasión, como un gesto intrusivo, que puede producir un sentimiento de repulsa. Hasta se ha llegado a hablar de la eyaculación de la mirada. Cuando ésta se evita habitualmente se acompaña con ello emociones negativas tales como ansiedad, vergüenza, turbación...

Según (Knapp, 1992:257) asociamos los movimientos de los ojos con una amplia gama de expresiones."Las miradas hacia abajo se asocian con la modestia; los ojos de 
mirar bien despierto se asocian con la franqueza, el asombro, la ingenuidad o el terror"

Hay apreciables diferencias culturales. Entre los árabes es normal mirarse atentamente a los ojos mientras conversan. En el extremo contrario, las sociedades del Lejano Oriente, esto se consideraría de mala educación. La costumbre americana es cambiar continuamente la mirada de uno a otro ojo o apartarla del rostro por completo. La forma de mirar en lugares públicos varía también de un lugar a otro. Según F. Davis en algunos países se admite que un hombre mire descaradamente a una mujer en la calle lo que en un país musulmán podría merecer un castigo.

Generalmente la mirada fija es un tabú que la comunicación audiovisual ha acogido en su código. La mirada directa a la cámara es algo que se reserva para ocasiones especiales. "Las películas también tienen en cuenta el tabú de la mirada fija. Una de las diferencias más notables entre las películas comerciales y las familiares es que en estas últimas la gente mira directamente a la cámara, como reconociendo la presencia del auditorio", según afirma (Davis, 1992: 88)

Existen también marcadas diferencias individuales. Las personas extravertidas emplean más la mirada y ésta es más larga e intensa que en las personas intravertidas. Personas con una fuerte necesidad de afiliación emplean la mirada en situaciones de amistad o colaboración. Personas dominantes hacen uso de la mirada en situaciones competitivas.

Las mujeres dan más importancia a la acción visual, observan más en situaciones de colaboración, afiliación o cuando muestran interés en el galanteo. En todas las culturas las mujeres dan mucha importancia a la pintura de los ojos para "capturar" la mirada. 
La atracción sexual e interpersonal se codifican y descodifican en función de las miradas. También se han hecho experimentos sobre la dilatación de las pupilas comprobando que éstas se dilatan siempre que lo que capta la mirada sea del agrado o del interés de la persona. Por otra parte la dilatación de las pupilas en una persona hace que ésta resulte más atractiva. La evidencia científica de que se produce una reacción ante el aumento del tamaño de las pupilas de otra persona lo suministró un experimento en el que se mostró a varios hombres dos fotografías de una misma chica idénticas salvo en el tamaño de las pupilas, que habían sido retocadas. En una de ellas fueron agrandadas y en la otra achicadas considerablemente. Las respuestas de los hombres, medidas por la reacción de sus propias pupilas fueron más del doble de fuertes ante la foto que tenía las pupilas agrandadas. Piénsese en el efecto en los espectadores de "Casablanca" ante las pupilas de I.Bergman o ante las pupilas de Vanesa Redgrave en "Camelot".

Está también comprobado que la comunicación visual, mirar y ser mirados, aumente la autoestima.

Por último señalemos la importante función de refuerzo que cumple la mirada como señal: propiciando un encuentro, en el saludo, o como complemento de la comunicación verbal indicando que se ha entendido la idea o sincronizando la conversación marcando los tiempos de hablar y escuchar, señalando "es tu turno".

2.3. En Japón y en todas las culturas de pensamiento budista, culturas del Zen, en las que el silencio es una virtud, como entre los indios, los gestos eran muy utilizados variando según sexo, rango, edad y clase. Se puede decir que los gestos se habían convertido en verdaderos lenguajes.

Pensemos en el valor y la significación de los gestos en ritos y liturgias o en valor que tienen los gestos para un sordomudo. 
La cinesis, la ciencia que estudia los gestos y los movimientos del cuerpo desde el punto de vista comunicativo, clasifica las culturas según la cantidad y las características de la comunicación gestual. Coloca primero las culturas mediterráneas y de Oriente Medio. Los nórdicos y, sobre todo, los anglosajones consideran la gesticulación de estos pueblos exuberante, pasional y decididamente exagerada

De acuerdo con (Davis,1992:48) "Algunas palabras van acompañadas de "marcadores" definidos, especialmente pequeños movimientos de cabeza, de ojos, de manos, de dedos o de hombros. Los gestos y movimientos ilustran gráfica y enfáticamente lo que se dice en la comunicación verbal y no verbal. Al igual que la mirada definen el ritmo, facilitan el sincronismo permiten actuar a los elementos de la interacción y ellos mismos se constituyen en tales. Este lenguaje de los gestos se observa muy bien en los coloquios o talk-show de televisión cuando el realizador es consciente de esta comunicación complementaria a las palabreas y con la planificación hace que ese lenguaje llegue a ser percibido por un público menos conocedor de los mecanismos de la comunicación.

Atendiendo al tipo de información que suministran se puede establecer esta clasificación de los gestos:

\section{GESTOS CONVENCIONALES}

En un ámbito cultural determinado tienen un significado objetivo. Son gestos simbólicos como los de los rituales o como la danza. No son siempre traducibles a palabras y si lo son no suelen tener la misma carga emotiva que llevan consigo como puros gestos 


\section{GESTOS QUE EXPRESAN ESTADOS EMOCIONALES}

Un primer grupo dirigidos a nosotros mismos, generalmente movimientos de automanipulación: autoeróticos, movimientos de autoadaaptación (preocupación por la propia imagen). Frecuentemente este tipo de gestos en público se inhiben o se manifiestan inconscientemente.

Un segundo grupo que se enmarcan en las actitudes interpersonales dirigidos al cuerpo de los demás. Unas manos oblicuas respecto al cuerpo significan defensa, los movimientos inquietos de manos y pies significan deseo de huida, la exposición de determinadas partes del cuerpo invitación o sugerencia sexual.

Siguiendo a (Knapp,1992:23)" Puesto que en la aparición de estas conductas de adaptación parece haber represiones sociales, se aprecian con mayor frecuencia cuando un individua está solo. Entonces cabe encontrar el acto completo y no un fragmento del mismo". Esta frase vendría a justificar la clasificación que hemos hecho viniendo a admitir que existen unos gestos para uno mismo, puesto que solamente se ejecutan cuando estamos solos y otros de carácter social que se ejecutan en el ámbito de lo social o lo interpersonal.

$\mathrm{Al}$ igual que cualquier otro de los lenguajes no verbales existe gran diferencia entre los distintos ámbitos culturales: "En realidad cada cultura otorga un significado a unos pocos de los innumerable movimientos anatómicamente posibles para el cuerpo humano" asegura (Davis,1992:46).

2.4. Otro aspecto a estudiar en la comunicación no verbal es el comportamiento en el espacio. Se pueden observar como los cambios de posición en el espacio se convierten en señales de interacción. 
El uso humano del espacio indica condicionamientos culturales, sociales y emocionales, así como por la estructura física del ambiente y las variables de la personalidad. Observemos el significado del uso del espacio en tres parámetros:

Altura: solo hace falta pensar en estructuras tales como el podium, el púlpito, el escenario, las tribunas para los mítines. La elevación de estos espacios sobre las personas asistentes a los actos que se celebran ante ellos da muestra de que se crea un rango superior con la altura. La estatura de los individuos no escapa a esta observación. Fijémonos en como entre los militares los generales y mandos superiores tienen normalmente mayor estatura que los suboficiales y la tropa. Lo mismo ocurre en la Iglesia siendo los cardenales y obispos más altos que el clero llano. Algo definitivo sobre el valor de la estatura nos lo enseña (Knapp,1992:157) en este párrafo: "La discriminación contra el hombre bajo se ve comprobada también por el estudio de ciento cuarenta patrones a quienes se pidió que eligieran entre dos hombres mediante la simple lectura de sus solicitudes de empleo. Las solicitudes eran exactamente iguales, salvo que una consignaba una talla de 1's3 mt, mientras que la otra consignaba una talla de 1'65 mt. Solo alrededor del diez por ciento de los patronos favorecieron a los hombres bajos.

Después de conocer estos datos sobre el valor de la estatura no es de extrañar la lucha de Hitler y Musolini por ocupar el lugar más alto en la famosa secuencia de la barbería de "El gran dictador". Ni puede extrañar el uso del contrapicado siempre que queramos dar estatura, física o moral a un personaje.

Proximidad: son normales en un encuentro entre personas los cambios de proximidad y orientación, gran parte de ellos de naturaleza social y que sobre todo son signos de atracción o rechazo; en una relación hostil preferimos observar al otro manteniéndonos a distancia. Las personas de alto status se mantienen en un frío distanciamiento como rechazo al contacto. En cambio es frecuente que haya 
proximidad entre personas del mismo rango o que a pesar de las diferencias de status mantienen una relación de colaboración o amistad. En "El halcón Maltés" Bogart es un detective que no mantiene con su secretaria una relación jerárquica sino de amistad y colaboración. Ésta se sienta sobre la mesa de trabajo de su jefe y en esa posición mantiene con él una conversación. Esta secuencia nos proporciona uno de los datos claves en la caracterización del personaje del detective Marlow.

A veces la indumentaria juega un papel importante como refuerzo en la acentuación de la proxémica. Pensemos en la decimonónica crinolina y sabremos como habemos de tener en cuenta este aspecto para manejar con todas sus posibilidades el vestuario en una película de época pues su intervención en el comportamiento de los personajes no es en absoluto desdeñable.

Postura: Estar de pie, sentado o apoyado puede ser clave en la caracterización de un personaje. Una postura de insolencia o de indolencia puede definir el carácter de un individuo. Según los estudios realizados la postura acompaña a la conversación como lo hacen los gestos solo que más lentamente. También es señalada la conexión entre la postura y las convenciones sociales y los rituales.

Existen dos dimensiones fundamentales con respecto a la posición del cuerpo:

Intimidad: se denota por la inclinación del cuerpo hacia delante, la proximidad y la orientación directa: su efecto es la reducción de la distancia y mejorar la comunicación visual. Otro signo es la apertura de brazos y piernas

Distensión: se denota por la simetría de brazos y piernas, la relajación de las manos, reclinación hacia atrás para personas gratas o de status más bajo o del sexo contrario. Las personas más importantes se sientan en posturas más relajadas. 
Otros componentes en posturas son los signos de dominio: erguido, cabeza hacia atrás; sumisión: menos erguido, cabeza inclinada hacia adelante.

No cabe duda de que existe una relación entre postura y personalidad aunque también cabe una presentación intencional. Personas tímidas y en estado de ansiedad se defienden apareciendo en posturas de agresividad. Podemos considerar la postura como una expresión de la imagen del propio cuerpo por lo que es frecuente enseñar los rasgos más atractivos ocultando los menos atractivos.

2.5. El aspecto externo es la señal que más influye en las percepciones dentro de las no verbales. Algunos elementos están bajo control:el vestuario, el peinado, las formas ornamentales; otros están solo parcialmente dominados: la piel, el rostro, el pelo o el físico. Se pone cuidado en poner de manifiesto lo agradable. Las personas atractivas gustan, es de todos conocida la importancia de la seducción. La importancia del aspecto externo es tanta que a las personas atractivas se les atribuyen rasgos positivos de personalidad. Se les considera mas cálidos y activos particularmente en el terreno de la sexualidad, más sensibles, mas educados, interesantes, dueños de si mismos, sociables.

Hay muchas personas que están fuertemente condicionadas por el cuidado de su propio cuerpo: adolescentes, personas de personalidad inestable, personas influidas por la reacción de los demás, las que desarrollan gran actividad social, las que quieren ser aceptadas en determinados grupos.

En el extremo contrario se observa un abandono del cuidado en ancianos, en disminuidos físicos y psíquicos, en marginados y en personas sin motivaciones. También se observa un abandono por razones ideológicas como es el caso de los hippies o contestatarios en general, o el abandono por estar inmersos en sus propios 
pensamientos. A veces el abandono o el rechazo al cuidado del aspecto externo se convierten en moda como es el caso de los pantalones vaqueros.

La apariencia es el resultado de la arquitectura anatómica del cuerpo y de todas sus modalidades expresivas. Disociados de esta actividad comunicativa los elementos de la indumentaria pierden su función significante. Tal ocurre cuando vestimos un objeto inanimado como un maniquí o un espantapájaros.

Digamos con (Squicciarino,1990:39) que: “Como parte de un todo dinámico y armónico, el vestido siempre significa algo, transmite importantes informaciones en relación con la edad, con el sexo, con el grupo étnico al que el individua pertenece, con su grado de religiosidad, de independencia y con su originalidad o excentricidad, así como con su concepción de la sexualidad y del cuerpo.

El aspecto externo es la expresión de la actitud hacia los demás. Indica el nivel de disponibilidad sexual, agresividad, rebeldía, sumisión, formalidad. Es, por supuesto, indicativo del status social y económico. También se usa para compensar sentimientos de inferioridad individual o social.

\section{Bibliografía}

AGAMBEN, Giorgio. Notes sur le geste. En: Trafic No1.París.1991. Revue du Cinema. P.O.L.

DAVIS, Flora. La comunicación no verbal. Madrid. 1992. Alianza Editorial

EISENSTEIN, Sergei. Reflexiones de un cineasta.Barcelona.1970. Editorial Lumen

KNAPP, Mark. La comunicación no verbal.Barcelona.1992.Paidós 
PUDOVKIN, Vsévolod. 1972. El actor en el film. Buenos Aires. 1972. Ediciones Nieva Visión

SQUICCIARINO, Nicola. 1990. El vestido habla. Madrid. 1990. Cátedra

\section{Notas}

Nota 1: CFr .EISENSTEIN. Sergei. 1970. Reflexiones de un cineasta. Barcelona. Editorial Lumen. Pág. 137.

Nota 2: En efecto es posible hacer (de facere) algo sin hacerlo (de agere); por ejemplo el autor hace un drama (de facere, pero no de agere), inversamente el actor hace (de agere) el drama (pero no de facere) (traducción del autor del artículo). 